\title{
STUDY OF SOME EFFECTIVE PARAMETERS ON MECHANICAL SHELLING AND GRADING CORN CROP
}

\author{
EL-Fawal, Y. A.*
}

ABSTRACT

The experiment was carried out during the agricultural season of 20102011 at Gemmeiza Agricultural Research Station, Gharbia Governorate, to evaluate the performance of a shelling and grading corn machine (Italian - manufactured) for SC10 and TWC 310 corn hybrids with corn moisture content of 15,17, 19 and 21\%. The machine parameters under investigation, to evaluate the shelling processing, were relative peripheral drum speed (6.28; 7.07; 7.85 and $8.63 \mathrm{~m} / \mathrm{s}$ ) and drum clearance (30, 40 and $50 \mathrm{~mm})$. For grading performance evaluation, relative peripheral cylindrical screen speeds $(2.63 ; 2.38 ; 2.13$ and 1.88 $\mathrm{m} / \mathrm{s}$ ) and inclination angle of the cylindrical screen (zero; $4 ; 8$ and 12 degrees) parameters were assessed. Shelling and grading efficiency, machine productivity, grain losses, grain damage and power requirement were estimated. The results indicated that the optimum parameters by using $25 \mathrm{~kg}$ feed rate at shelling drum speed of $7.85 \mathrm{~m} / \mathrm{s}$, drum clearance of $40 \mathrm{~mm}$, cylindrical screen speed of $2.13 \mathrm{~m} / \mathrm{s}$, inclination angle of the cylindrical screen of 4 degree and grain moisture content ranging from 15 to $17 \%$.

\section{INTRODUCTION}

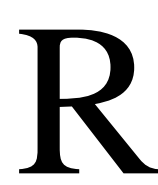

ecently, the government tends to enlargement the growing of corn to compensate the shortage of the wheat production and try to achieve self-sufficiency of bread by mixing corn with wheat with a percentage of $20 \%$. Husking, shelling, cleaning and grading are very important operations carried out on corn crop. Akcali and Guven (1990) reported that the three basic dimensions (L, W and T) are used to represent the agricultural materials quantitatively. However, measurements of the width and thickness may be reduced to a single parameter to represent grain geometrically the length and diameter parameters.

\section{*Researcher, Ag. Eng. Res. Inst., ARC.}


The correlation between diameter and length is important to describe the grain in a much simpler manner. Tarasenko and Merchalove (1996) studied the causes and probability of damage to harvested grain during drying, pre-cleaning, primary cleaning, secondary cleaning and intermediate storage. They reported that the damage to the grain decreased with decreasing probability of contact and with decreasing impact velocity with the working elements, transport distance, and number charging cycles.

Ismail (1981) stated that the slop of the sieve is a main factor affecting separation efficiency, which increased significantly by increasing the sieve slope up to 25 degrees in both vertical and lateral motion. While, in frontal motion, it tends to increase with increasing sieve slope at small stroke length and decreased at high stroke length. The separating efficiency was increased in the compound motion as the sieve slope is increased in the range from zero to 20 degrees, while at the higher slope, the separating efficiency tended to decrease. Srivastava et al. (1993) evaluated the performance of the cylindrical screen separator and concluded that, in general, the theoretical predictions were in close agreement with the experimental data. They also stated that a rotating cylindrical screen with an inner auger rotating at a faster speed is capable of separating grain from straw and the cylindrical screen was capable of transferring the straw axially and allowed a positive control on the tangential and axial crop motion. AJav and Igbeka (1995) found that the shelling efficiency of the Sheller varies with moisture content, speed of the shelling unit and feed rate. The machine had a shelling efficiency of $98 \%, 95 \%$ and $94 \%$ when shelling corn with a moisture content of 11, 20 and $25 \%$, respectively. The Sheller capacity was $260 \mathrm{~kg} / \mathrm{h}$. The performance tests proved that the Sheller performed best at shelling unit speed of $450 \mathrm{rpm}$ with minimum losses and high efficiency. Metwalli et al. (1995) reported that the triangle rasp - bar drums is strongly recommended for its good performance. The grain damage, unshelled grain and shelling efficiency were $3.86 \%, 1.95 \%$ and $96.2 \%$ respectively. At drum speed of $10.26 \mathrm{~m} / \mathrm{s}$ and at 1.8 to 2.1 inlet clearance / outlet clearance for 18 to $20 \%$ moisture content as a condition of the triangle rasp-bar drums. Ali (1998) reported that drum speed of $11.09 \mathrm{~m} / \mathrm{s}(530$ 
rpm) and seed moisture content of $9 \%$ are recommended for threshing chickpeas crop as in recorded both minimum losses and energy (3.07\% and $25.80 \mathrm{~kW} . \mathrm{h} / \mathrm{fed}$ ), respectively. Alonge and Adegbulugbe (2000) with grain thresher for maize and cowpeas found that the rate of shelling increased as the speed increased. Grain losses decreased as the speed increased but more breakages were recorded at high speed. The rate of shelling grain losses and breakages decreased as moisture content increased. Ebtsam (2000), studied threshing corn by combine harvester and found that, drum speed ranged from 9.42 to $10.99 \mathrm{~m} / \mathrm{s}(600-700 \mathrm{rpm})$, forward speed was 2.1-3.3 km/h and drum-concave clearance of 20/40 $\mathrm{mm}$. Kamel et al. (2002) indicated that increasing the harvesting forward speed from 1.3 to $4.8 \mathrm{~km} / \mathrm{h}$ tends to increase the field capacity from 0.67 to $1.86 \mathrm{fed} / \mathrm{h}$, and the highest value of total machine loss was $4 \%$ at cylinder speed of $13.2 \mathrm{~m} / \mathrm{s}$, using forward speed of $1.3 \mathrm{~m} / \mathrm{h}$ and kernel moisture content of $18 \%$. They also stated that the manual harvesting operation is very expensive comparing with the mechanical harvesting. Amin (2003) studied that the effect of mechanical properties on grading efficiency and found that the separating efficiency increased by increasing the time of separation from 3 to $12 \mathrm{~min}$, cylinder speed from 375 to 750 Osco/min for vibratory machine, and from 50 to $250 \mathrm{rev} / \mathrm{min}$ for rotary machine, and inclination of sieves up to 9 degrees. Mady (2004) found that the suitable level of kernel's moisture content during shelling operation was $15.5 \%$ with cylinder speed of $450 \mathrm{rpm}$ and concave clearance of $50 \mathrm{~mm}$ which reduced the broken kernels up to $6.5 \%$ and increased the whole kernels up to $93.5 \%$. El-Shal (2007) developed and evaluated the performance a Pakistanian corn shelling machine and found that the optimum drum speed and concave clearance for shelling both yellow and white corn varieties were $6.29 \mathrm{~m} / \mathrm{s}$ (500 rpm), and $40 \mathrm{~mm}$, respectively. The objectives of the research is evaluate the performance of a shelling and grading corn machine.

\section{MATERIALS AND METHODS}

The present experiment was carried out at Gemmeiza Agricultural Research Station, El-Gharbia Governorate during 2009 and 2010 seasons. To achieve the objective of this study, four different moisture contents 
(15;17; 19 and 21\%), four peripheral drum speeds (400; 450; 500 and $550 \mathrm{rpm}$ ), three drum-concave clearances (30; 40 and $50 \mathrm{~mm}$ ), four peripheral cylindrical screen speeds $(75 ; 85 ; 95$ and $105 \mathrm{rpm})$ and four cylindrical screen inclinations (Zero; $4 ; 8$ and 12 degrees) were investigated. The two of corn's hybrids varieties Single Cross 10 and Three-way Cross 310 were recorded under all experiments.

\section{The prototype descriptions}

The prototype consists of the main frame, power source and power transmission system and shelling units. As shown in figure-1, the shelling unit is having the feeding system, drum, concave conveying mechanism and grading units.

Feeding material was a manual feed through a rectangular opening $(60 \times$ $40 \mathrm{~cm}$ ). The drum consists of four parts, meanly, feeding screw; shelling plates, spike tooth and blower. The shelling plate has four plates with 40 $\times 4 \times 1 \mathrm{~cm}$ length, width and thickness respectively and each plate has two slotted opening $3 \times 1.5 \mathrm{~cm}$ length and width to allow the operator adjusting clearance. The plate can be moved up and down on its base to allow clearance adjusting. It is supported horizontally by two pillow block bearing, located and fixed in the machine frame, (crush cob unit discharges).

The centrifugal blower is the end part for discharge cobs ( 3 blades, $13 \times 8$ $\mathrm{cm}$ length and width. The concave is the cylindrical shape with outer diameters (O.D.) of $40 \mathrm{~cm}$ and $180 \mathrm{~cm}$ length. It is fabricated from steel sheet of $4 \mathrm{~cm}$ in thickness with round perforated holes (18 cm O.D.).

The conveying unit mechanism as shown in Fig. 2 consists of two screws fabricated from the solid shaft conveyor (3 cm O.D.); $180 \mathrm{~cm}$ length inside the cylindrical tube $(20 \mathrm{~cm}$ O.D.). The first one is mounted horizontally under the shelling unit to conveying the shelled grain to the second screw which is equipped vertically for conveying the grain to the grading unit.

The grading unit having the cylindrical screen $(50 \mathrm{~cm}$ O.D. and $200 \mathrm{~cm}$ length) with four discharge spouts as shown in Fig. 3. It is divided to four parts. The first part has $60 \mathrm{~cm}$ in length with $0.8 \mathrm{~cm}$ round holes. The second has $60 \mathrm{~cm}$ in length with $0.95 \mathrm{~cm}$ round holes. The third parts have $60 \mathrm{~cm}$ in length with $1.1 \mathrm{~cm}$ round holes, and the fourth has $60 \mathrm{~cm}$ 


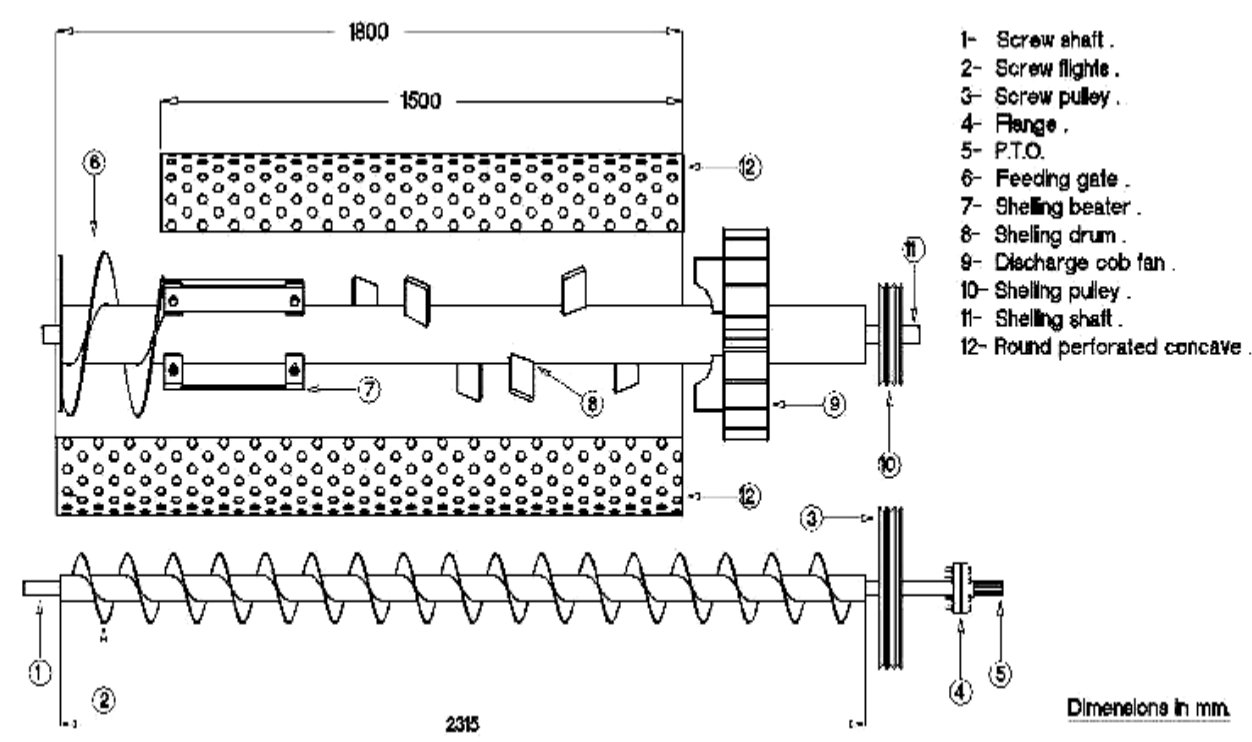

Fig. 1: Elevation view of the shelling unit

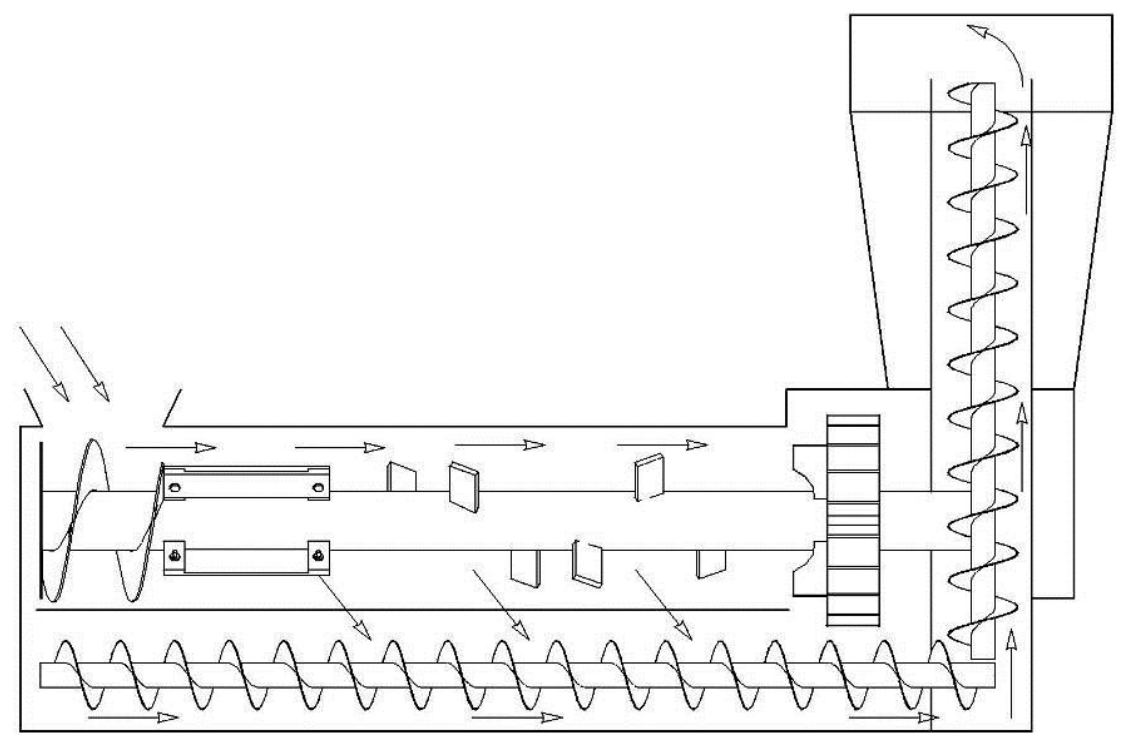

Fig. 2: Sketch of the conveying mechanism 


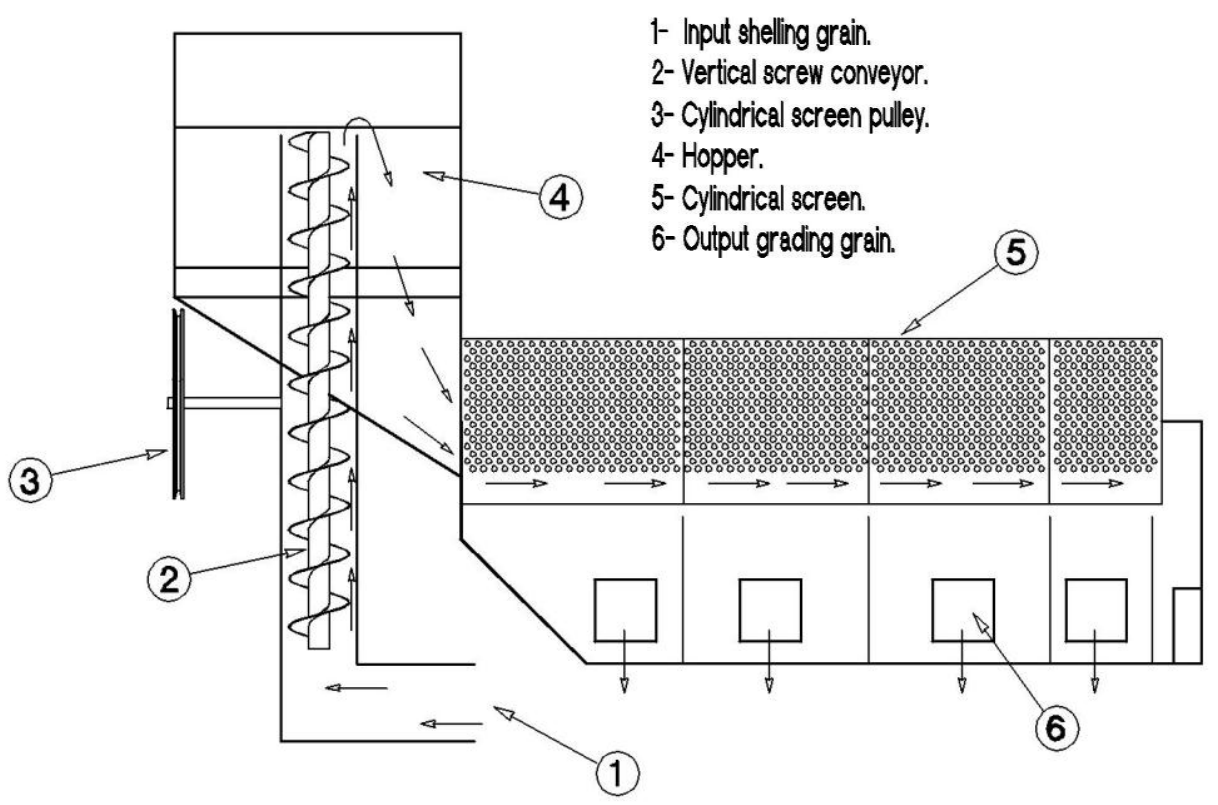

Fig. 3: Elevation view of grading unit

in length with $1.25 \mathrm{~cm}$ round holes. The inclination of the cylindrical screen can be adjusted in four positions namely (Zero; 4; 8 and 12 degrees), the frame of the cylindrical screen has four spouts installed on it. Every spout in a position towered above each part of the cylindrical screen and has some slope to facilitate the seed discharge.

\section{Power source and power transmission system:}

The prototype is operated by pulleys and V- belts. The power source utilized in this machine in a tractor of $45 \mathrm{~kW}$ at rotating speed of $540 \mathrm{rpm}$ PTO transmitted directly to all other movable parts of the machine. The main shaft pulley $(10 \mathrm{~cm}$ O.D.) is fitted secured rigidly to its axis. This pulley transmits the power to the pulley $(10 \mathrm{~cm}$ O.D.) fitted secured on the shelling drum shaft, and to the pulley (52 cm O.D.) fitted secured on the cylindrical screen shaft.

\section{Peripheral drum speeds:}

The channel of the tractor fuel lever has four scribed marks $1 ; 2 ; 3$ and 4. The selection PTO speed in (rpm) can be done by setting of or change the position of the fuel lever to scribed marks on the fuel lever channel. The highest speed in $550 \mathrm{rpm}$ was obtained when the fuel lever in the first 
number 1, and the last number 4 provides the lowest speed of $400 \mathrm{rpm}$. While the $(52 \mathrm{~cm}$ O.D.) of the cylindrical screen pulley achieved the obtained peripheral cylindrical screen $(75 ; 85 ; 95$ and $105 \mathrm{rpm})$ corresponding a liner cylindrical screen speeds of $(1.95 ; 2.22 ; 2.48$ and $2.75 \mathrm{~m} / \mathrm{s}$ ) respectively.

Electronic digital caliper was used for measuring the dimensions of grain and ear cob. The speed of rotating shafts in rpm was measuring by Hand Contact Tachometer. The Digital-Hydrometer was used for measuring the wet moisture content in percentage.

\section{The grain damage:}

1- Visible grain damage (external damage) was calculated as follows:

$$
S_{d}=\frac{W_{d}}{W_{s}} \times 100
$$

\section{Where:}

$S_{d}$ : Grain damage, $\%$.

$W_{d}$ : mass of damage grains, $\mathrm{g}$.

$W_{s}$ : Total grain mass, $100 \mathrm{~g}$.

2- Invisible grain damage (internal) in the percentage of the invisible grain damage was calculated as follows:

$$
\mathrm{I}_{\mathrm{d}}=\frac{a}{b} \times 100
$$

\section{Where:}

$\mathrm{I}_{\mathrm{d}}:$ Invesible grain damage, $\%$

a : Number of ingeminated grain from the samples taken after shelling operation.

$\mathrm{b}$ : Total grains of the sample.

\section{Shelling losses:}

The grain losses values were classified into unshelled grains and free grains at out let of cobs.

Unshelled grains was calculated in the percentage as follows: 


\section{Where:}

$$
L_{k}=\frac{W_{2}}{W_{1}+W_{2}+W_{3}} \times 100
$$

$L_{k}$ : Unshelled percentage.

$W_{l}$ : mass of shelled grains, $\mathrm{kg}$.

$W_{2}$ : mass of unshelled grains, $\mathrm{kg}$.

$W_{3}$ : mass of shelled and received at the outlet of cobs, $\mathrm{kg}$.

Free grains with cobs: The percentage calculated as follows:

$$
\begin{gathered}
L_{c}=\frac{W_{3}}{W_{1}+W_{2}+W_{3}} \times 100 \\
\text { Total losses }=L_{k}+L_{c} \%
\end{gathered}
$$

\section{Shelling efficiency:}

Shelling efficiency of corn sheller (E) was estimated as follows:

$$
E=100-L_{k} \quad \%
$$

\section{Grading efficiency, \%:}

A randomized sample of 500 grains were taken from each spout for measuring seed width and compare with the hole diameter at the existing cylindrical screen, then the efficiency calculated as follows:

$$
\eta_{G}=\frac{S_{W}-S_{W o}}{S_{W}} \times 100
$$

Where:

$\eta_{G}$ : Grading efficiency per one sector.

$S_{W}$ : Sample weight, $\mathrm{g}$

$S_{W o}$ : Off-sized seeds (equal and under sized seeds)

then the total grading machine efficiency calculated as follows:

$$
\eta_{G m}=\eta_{G 1} \times \eta_{G 2} \times \eta_{G 3} \times \eta_{G 4}
$$

Machine productivity and efficiency: It can be determined according to (Amin, 2003) as follows: 


$$
W=m_{i} \times \frac{60}{t}
$$

\section{Where:}

$W$ : Capacity of the machine, ton/h.

$m_{i}$ : Mass of classified crops from unit, ton.

$t$ : Shelling and grading time, min.

The efficiency of the machine can be estimated from the following equation:

$$
\eta_{\mathrm{o}}=\frac{m_{i}}{m} \times 100
$$

\section{Where:}

$\eta_{0}$ : The efficiency of machine, $\%$.

$m_{i}$ : Total mass of crops throughout of the machine, ton.

\section{RESULTS AND DISCUSSION}

\section{The unshelled grain losses}

Regarding to drum-concave clearance, results indicated that increasing concave clearance from 30 to $50 \mathrm{~mm}$ tends to increase the unshelled grain losses from $1.16 \%$ to $5.26 \%$ and from $1.61 \%$ to $5.56 \%$ for shelling SC10 and TC310 corn hybrids, respectively at drum speed of $400 \mathrm{rpm}$, as shown in Fig. 4. On the other hand, increasing to drum speed from 400 to $500 \mathrm{rpm}$ leads to decrease the unshelled grain losses from $1.16 \%$ to zero $\%$ and from $1.61 \%$ to zero $\%$, respectively at the drum-concave clearance of $30 \mathrm{~mm}$.

The free grain losses (Fig. 5) at the outlet of cobs generally increased with increasing drum speed. Data cleared out that the free grain losses increased from $2.40 \%$ to $6.86 \%$ and from $2.55 \%$ to $7.00 \%$ by increasing the drum speed from 400 to $550 \mathrm{rpm}$ for shelling SC10 and TC310 corn hybrids, respectively at drum-concave clearance of $30 \mathrm{~mm}$. Regarding to drumconcave clearance increasing concave clearance from 30 to $50 \mathrm{~mm}$ tends to decrease the free grain losses from $2.40 \%$ to $1.57 \%$ and from $2.55 \%$ to $1.72 \%$ for shelling corn (SC10 and TC310) respectively as shown in Fig.5 at drum speed of $400 \mathrm{rpm}$. These results may be due to increasing the 
shelling force at the highest drum speed up to the consistence force between the grain ant the ear.
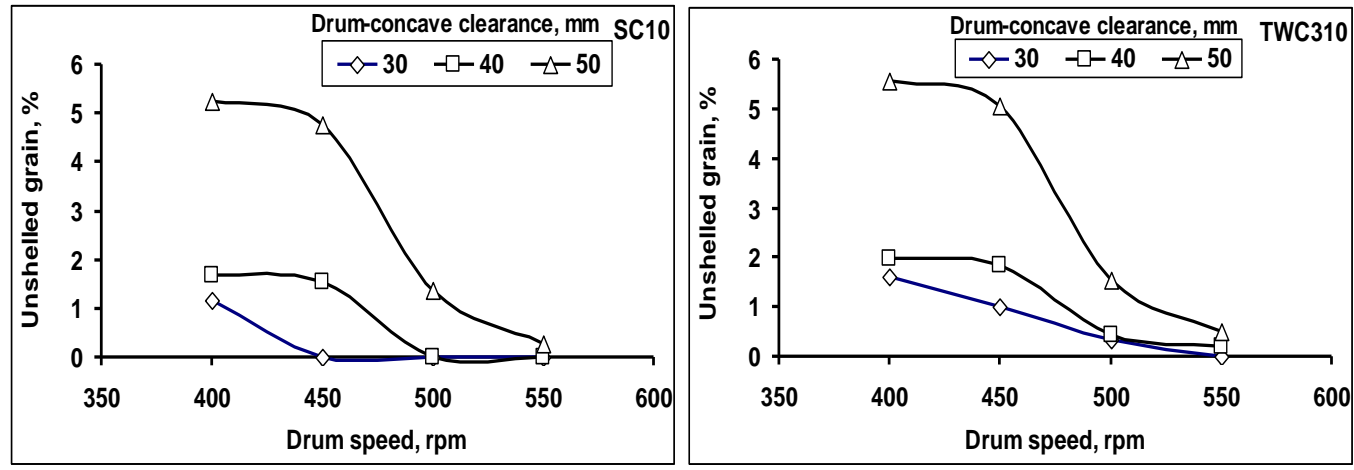

Fig. (4): Effect of peripheral drum speed on the unshelled grain \%
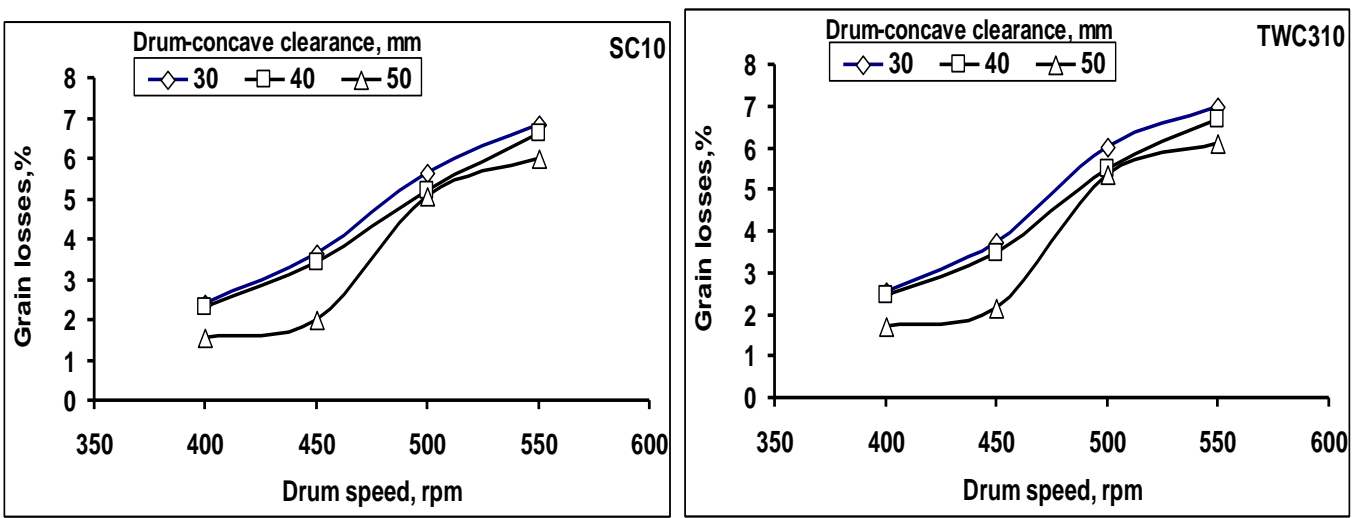

Fig. (5): Effect of peripheral drum speed on grain losses\%

\section{The visible and un-visible grain damage:}

The represented data show that the visible grain damage increased with increasing drum speed (Fig. 6). It increases from $2.68 \%$ to $3.26 \%$ and from $2.98 \%$ to $3.56 \%$ by increasing the drum speed from 400 to $550 \mathrm{rpm}$ for shelling SC10 and TC310 corn hybrids, respectively at drum-concave clearance of $30 \mathrm{~mm}$. Regarding to drum-concave clearance, the visible grain damage decreased with increasing concave clearance. Results indicated that increasing concave clearance from 30 to $50 \mathrm{~mm}$ tends to decrease the visible grain damage from $2.68 \%$ to $0.50 \%$ and from $2.98 \%$ to $0.80 \%$ for shelling corn (SC10 and TC310) respectively as shown in Fig. 6 at drum speed of $400 \mathrm{rpm}$. 
The data as shown in Fig. 7 indicated that the invisible grain damage increased with increasing drum speed. The increases the invisible grain damage was from $2.41 \%$ to $3.36 \%$ and from $2.66 \%$ to $3.86 \%$ by increasing the drum speed from 400 to $550 \mathrm{rpm}$ for shelling SC10 and TC310 corn hybrids, respectively at drum-concave clearance of $30 \mathrm{~mm}$. This is due to the increasing of grain impacts on the drum. Regarding to drum-concave clearance, results show that the invisible grain damage decreased as concave clearance increased because of the decrease of friction between grains and drum. The results indicated that increasing the concave clearance from 30 to $50 \mathrm{~mm}$, tends to decrease the invisible grain damage from $2.41 \%$ to $1.85 \%$ and from $2.66 \%$ to $2.01 \%$ for shelling corn (SC10 and TC310) respectively at drum speed of $400 \mathrm{rpm}$.

\section{Grain damage}

Relating to the grain moisture content, the obtained results show the effect of the moisture content at different drum (peripheral speed and drum-concave clearance), the grain damage percentage (visible and invisible) at the average of the corn varieties increased as moisture content increased from 15 to $21 \%$. Fig. 8 shows that seed damaged percentage was high at grain moisture content ranged between 17 to $21 \%$ and there is the slight difference of grain damage percentage when moisture content increased from 15 to $17 \%$. On the other hand, when moisture content increased from 17 to $21 \%$ grain damage percentage increased sharply, this is not recommended. So the best moisture content rang for shelling and grading corn is 15 to $17 \%$.

The highest value of percentage grain damage was $9.8 \%$ at the highest drum peripheral drum seed of (550 rpm) with the lowest drum- concave clearance of $(30 \mathrm{~mm})$ at the highest moisture content level of $21 \%$. While the lowest percentage seed damage value was $1.51 \%$ at the lowest peripheral drum seed of $400 \mathrm{rpm}$ with the largest drum-concave clearance of $50 \mathrm{~mm}$ the lowest moisture content level of $15 \%$. 

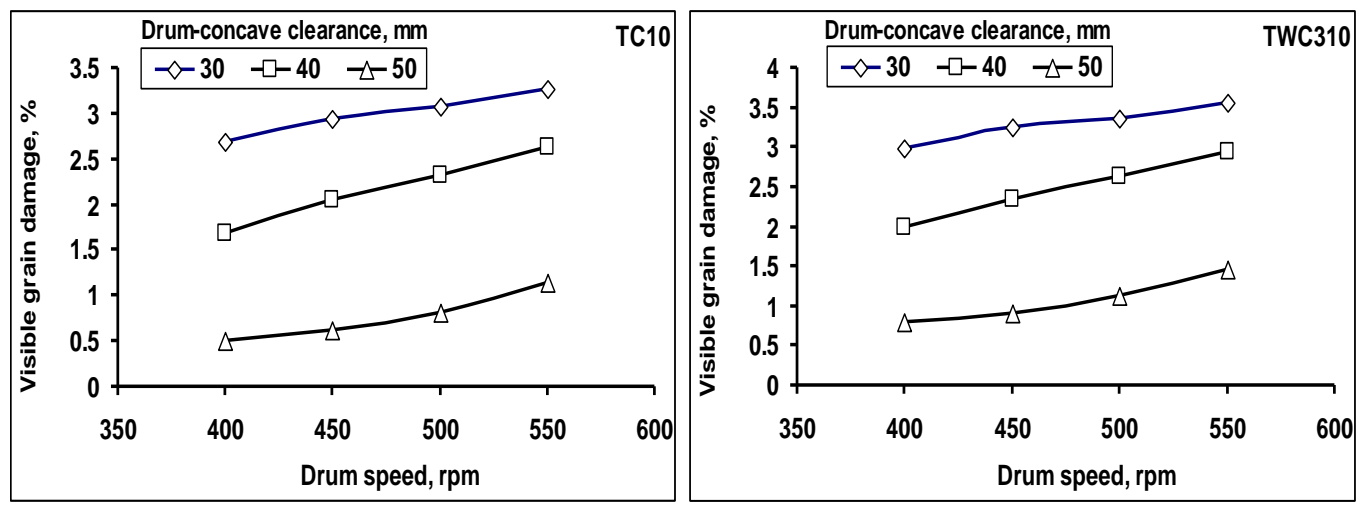

Fig (6): Effect of peripheral drum speed on visible grain damage.
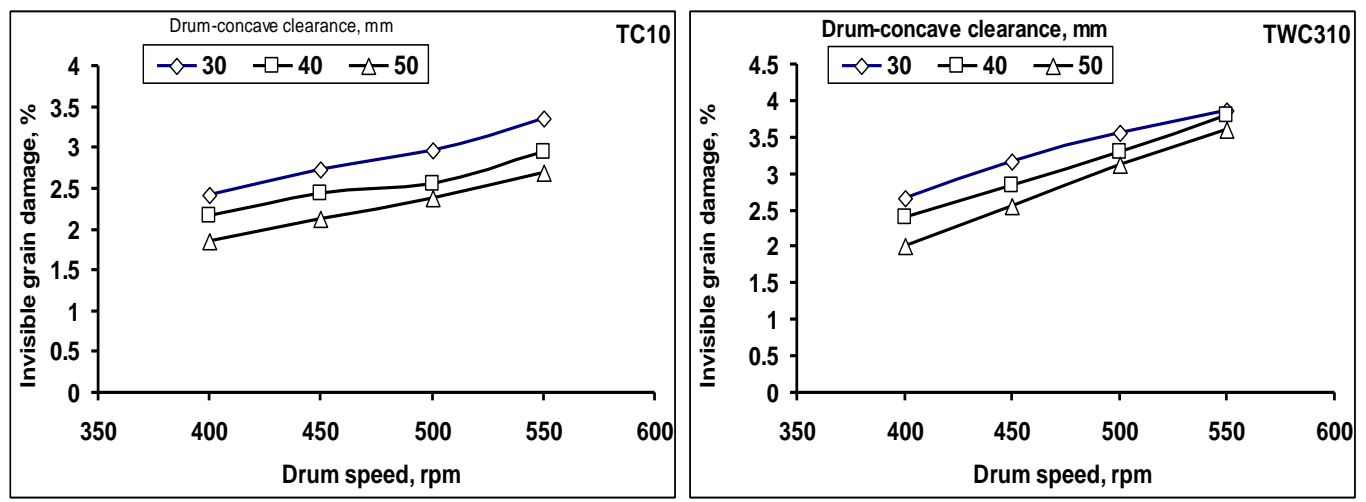

Fig (7): Effect of peripheral drum speed on invisible grain damage.
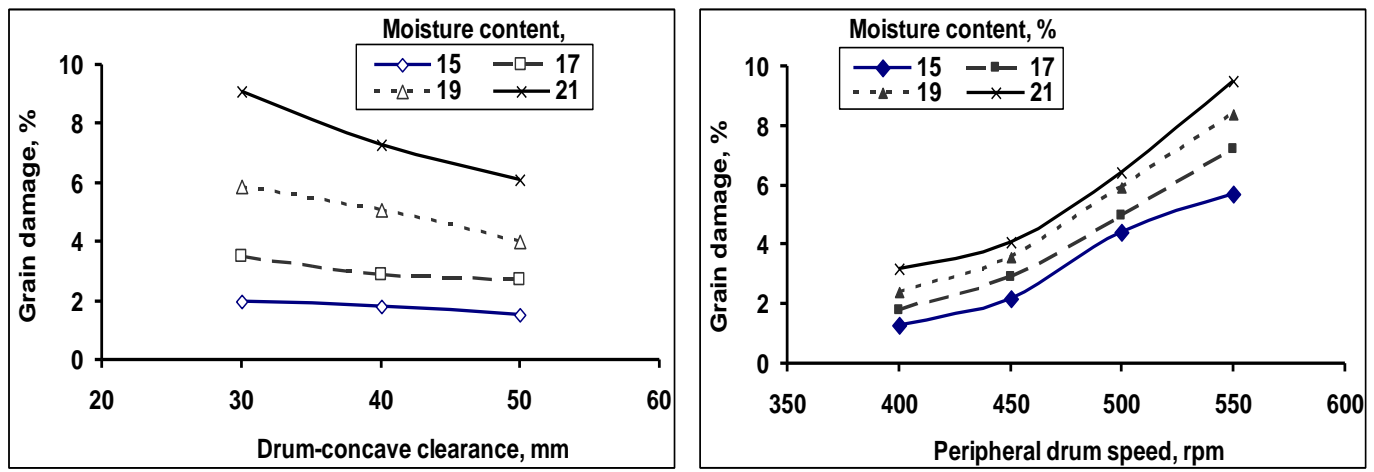

Fig. (8): Effect of different drum-concave clearances at different grain moisture contents. 


\section{The Shelling Efficiency:}

The shelling efficiency was affected by drum speed and concave clearance. Results indicated that the shelling efficiency increased with the increase of drum speed, where it reached $100 \%$ at the highest drum speed of $550 \mathrm{rpm}$ and $30 \mathrm{~mm}$ concave clearance. On the other hand, shelling efficiency decreased by increasing concave clearance. Where the grains cannot be separated easily and as a result, the percentage at unshelled grains increased for shelling corn (SC10 and TC310) respectively as shown in Fig. 9.
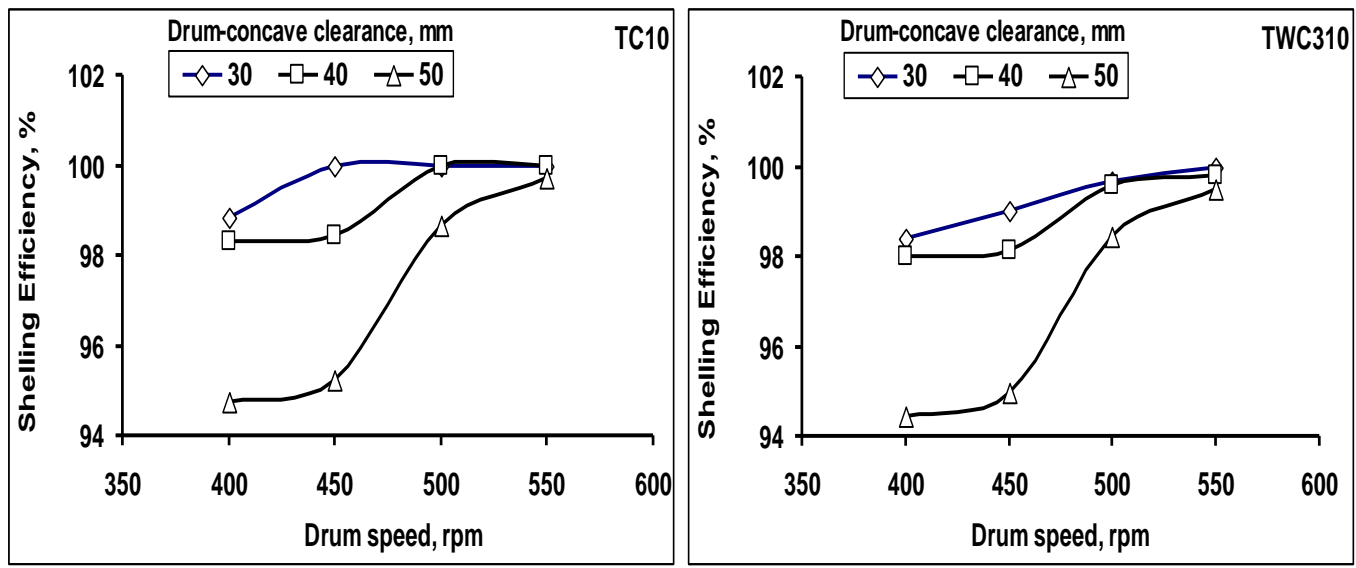

Fig (9): Effect of drum speed on shelling efficiency at different concave clearance.

\section{Grading efficiency}

Generally, the results show that the effect of cylindrical screen speeds and inclination angle on the grading efficiency where the grading efficiency increased with decreasing cylindrical screen speed and decreasing the inclination angle.

Data illustrated in Fig. 10 shows that the grading efficiency decreased by increasing cylindrical screen speed, increasing cylindrical screen speed from 1.88 to $2.63 \mathrm{~m} / \mathrm{s}$ ( 75 to $105 \mathrm{rpm}$ ), at the optimum of concave clearance $40 \mathrm{~mm}$ and drum speed of $8.63 \mathrm{~m} / \mathrm{s}(550 \mathrm{rpm})$, tends to decrease the grading efficiency from $92.64 \%$ to $82.26 \%$ and from $91.71 \%$ to $81.43 \%$. Regarding to the cylindrical screen inclination results show that the grading efficiency decreased as the inclination angle increased. 
The results indicated that increasing the inclination angle from zero to 12 degrees at the optimum of concave clearance $40 \mathrm{~mm}$ and drum speed of $8.63 \mathrm{~m} / \mathrm{s}(550 \mathrm{rpm})$ tends to decrease the grading efficiency from $92.64 \%$ to $85.68 \%$ and from $91.71 \%$ to $84.82 \%$, at cylindrical screen speed of $1.88 \mathrm{~m} / \mathrm{s}(75 \mathrm{rpm})$ for corn varieties (SC10 and TC310) respectively as shown in Fig. 10.

Finally, the speed of the cylindrical screen must be slowly to allow the grain to fit itself exactly in the opening and pass through. Therefore, the grading efficiency increased by decreasing the cylindrical screen speed and cylindrical screen inclination. This may be due to; the seed remains on the screen as long as possible to give every seed an opportunity to pass through an opening.
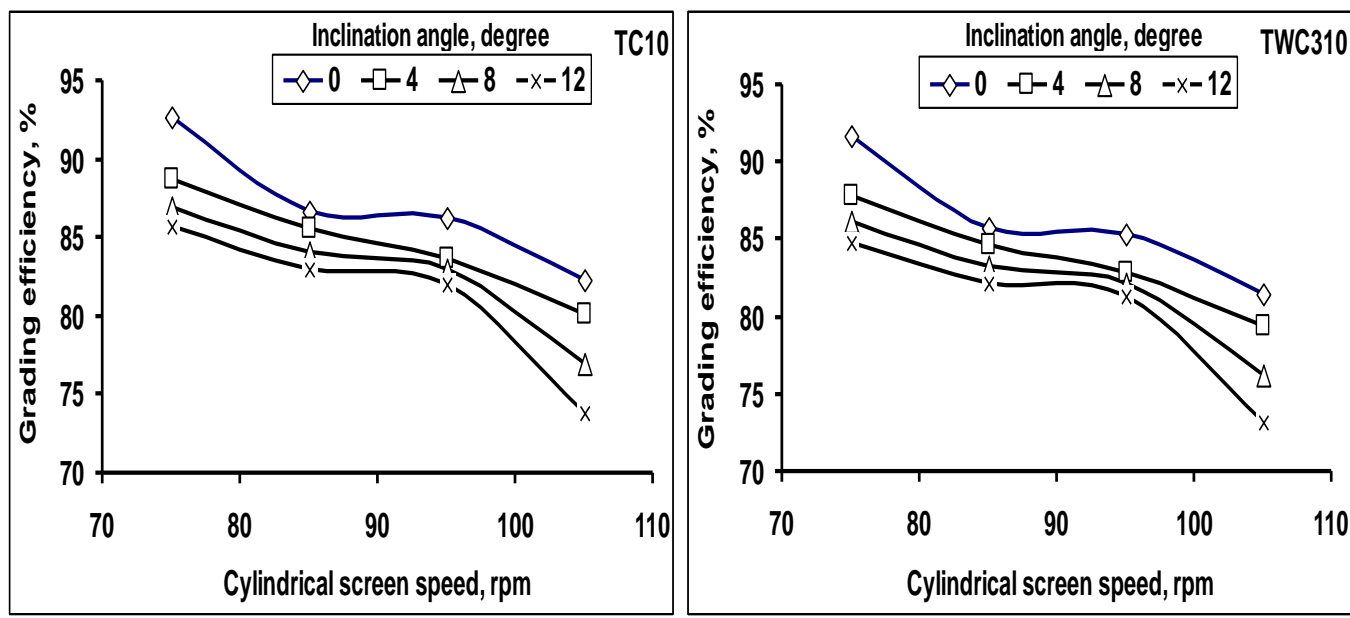

Fig (10): Effect of cylindrical screen speed on grading efficiency at different cylinder inclination angle.

\section{Productivity}

Generally, the results show that the effect of cylindrical screen speeds and inclination angle on the machine productivity where the productivity increased with increasing each of cylindrical screen speed and the inclination angle. For example, the productivity increased, from 0.32 to $0.47 \mathrm{Mg} / \mathrm{h}$ and from 0.30 to $0.43 \mathrm{Mg} / \mathrm{h}$ at cylindrical screen speed of 1.88 $\mathrm{m} / \mathrm{s}$ (75 rpm) for corn varieties (SC10 and TC310) respectively. Regarding to the inclination angle, the results indicated that increasing the 
inclination angle from zero to 12 degrees, tends to increase the productivity from 0.32 to $0.38 \mathrm{Mg} / \mathrm{h}$ and from 0.30 to $0.37 \mathrm{Mg} / \mathrm{h}$ at cylindrical screen speed of $1.88 \mathrm{~m} / \mathrm{s}(75 \mathrm{rpm})$ for corn varieties (SC10 and TC310) respectively as shown in Fig. 11.
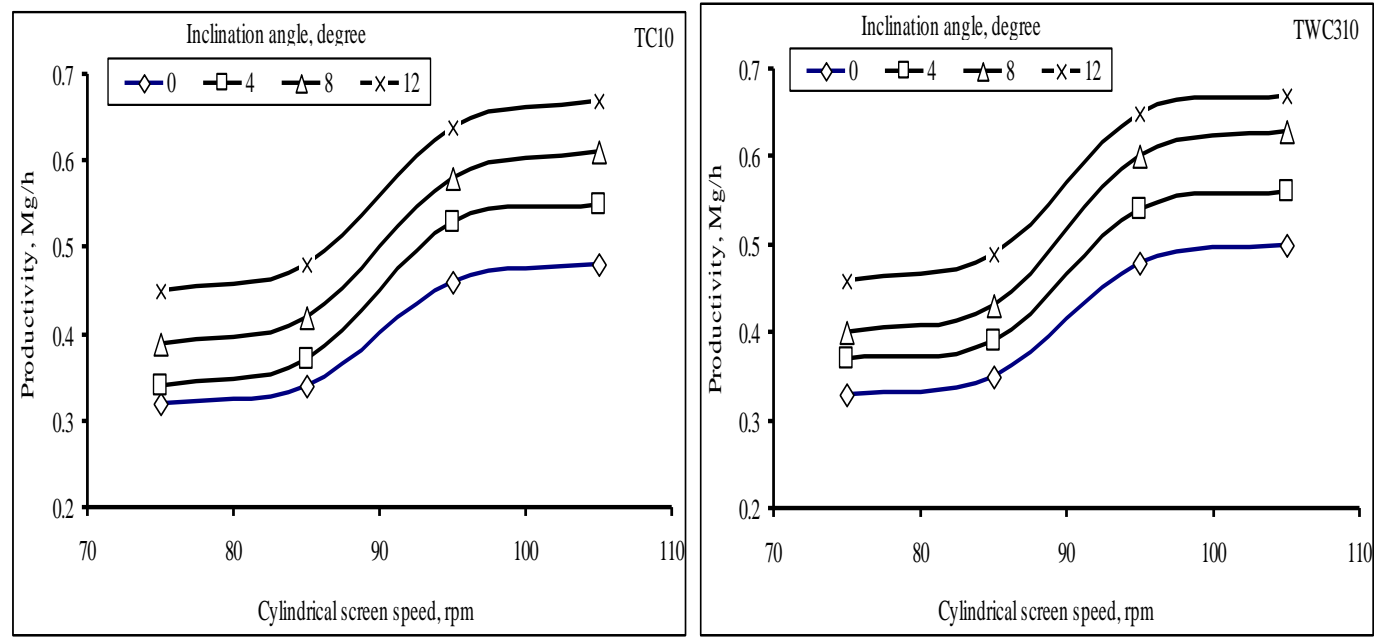

Fig (11): Effect of cylindrical screen speed on the productivity $(\mathrm{Mg} / \mathrm{h})$

\section{Power requirement}

The represented data in Fig. 12 shows that the power requirement increased with increasing function unit's speed. From the obtained data, clearly that increasing function unit's speed from the lowest to the highest operation speed tends to increase the power requirement from $6.51 \mathrm{~kW}$ to $12.05 \mathrm{~kW}$ for corn varieties of SC10 and TC310 respectively.
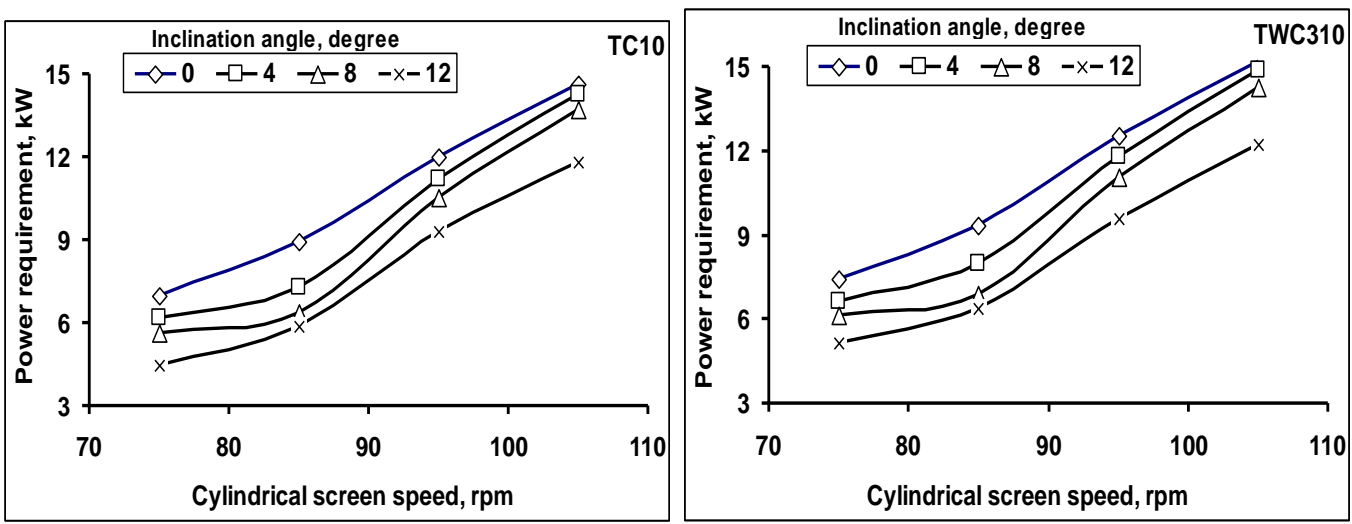

Fig (12): Effect of function unit speed on power requirement 


\section{CONCLUSION}

Conclusion of this study can be summarized as follow;

All the results showed that the optimum values of engineering and operational parameters for shelling processing were relative peripheral drum speed is $500 \mathrm{rpm}(7.85 \mathrm{~m} / \mathrm{s})$ with concave clearance $(40 \mathrm{~mm})$, also for grading processing peripheral cylindrical screen speed is 85 $\mathrm{rpm}(2.13 \mathrm{~m} / \mathrm{s})$ with inclination angle 4 degrees at moisture content $15-17$ $\%$ (d.b.) and feeding rate of $25 \mathrm{~kg}$.

\section{REFERENCES}

Ajav, E.A. and J.C. Igbeka (1995). Performance evaluation of a Nigerian maize sheller using an international test code. J. Agric. Eng. For 1. Dev., 2(1): 1-8.

Akçalı I.D. and O. Guven (1990). Physical properties of peanut in Turkey. Agricultural Mechanization in Asia, Africa and Latin America (AMA), Vol.21/3, 55-60.

Ali, M.M. (1998). Study on the mechanization of chickpea crop production under Egyptian conditions. M.SC., thesis, Agric. Eng. Dept. Fac. Agric. Zagazig University.

Alonge, A.F. and T.A. Adegbulugbe (2000). Performance evaluation of a locally developed grain thresher. II. AMA,. Agricultural. Mechanization. In. Asia-Africa. and. Latin. America. 31(2): 5254.

Amin, E.A. (2003). Effect of some physical and mechanical properties on grading efficiency. The 11th Annual Conference of Misr Society of Agr. Eng. Oct.2003 : 451-470.

Ebtsam, H.M. (2000). Developing a harvesting machine for grain crops in small farms M.Sc. Thesis. Agric. Eng. Dept. fac. Of Agric. Mansoura University.

El-Shal, Hanan. M.S. (2007). Development of an equipment for corn shelling. Ph.D. Thesis. Agric. Eng. Dept., Fac of Agric Zagazig Univ.

Ismail, Z.E. (1981). Evaluation of some parameter affecting corn. Misr j. oa Agric. Eng. 5 (4): 393-404. 
Kamel, O.M; M. E. Baddawy and H. A. El-Khateeb (2002). A study on some operating parameters affecting the performance of corn combines harvesting. Misr J. Agric, Eng., 19(4): 901-917.

Mady, M.A. (2004). Development and evaluation of a power operated corn Sheller. J. Agric. Sci. Mansoura University. 29(8): 46134628.

Metwalli, M.M; M.A. Helmy; S.M. Gomma and M.E. Badawy (1995). Evaluation of some parameters affecting corn Sheller performance. Misr J. Agric. Eng. 12(2): 439 - 455.

Srivastava, A. K.; C. E. Goering and R. P. Rohrbach (1993). Engineering Principles of Agricultural Machines. ASAE. Text book number, published by the American society of agricultural engineers, pp. 509545.

Tarasenko, A. P. and M.E. Merchalova (1996). Prospects for reducing seed damage during post harvest treatment. Traktory i sel, skokhoz yaistvennye mashiny, No. 11, 24, 25, Russian.

$$
\begin{aligned}
& \text { الملخص العربي } \\
& \text { دراسة بعض العوامل المؤثرة على تفريط وتدريج محصول الذرة آلياً } \\
& \text { د/ يحيى عبد السلام الفوال* }
\end{aligned}
$$

“باحث ـ معهة بحوث الهندسة الزراعية ـ مركز البحوث الزراعية. 